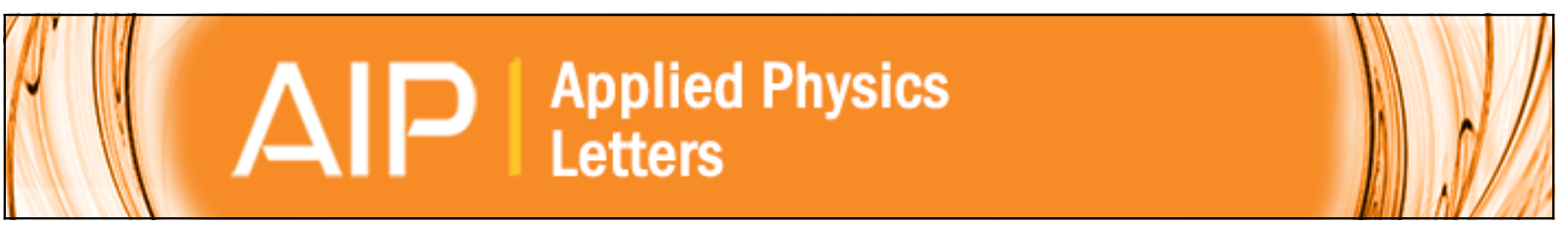

\title{
Uniform component of index structure induced in Ge-SiO 2 fibers by spatially modulated ultraviolet light
}

Tsung-Ein Tsai, Glen M. Williams, and E. J. Friebele

Citation: Applied Physics Letters 72, 3243 (1998); doi: 10.1063/1.121678

View online: http://dx.doi.org/10.1063/1.121678

View Table of Contents: http://scitation.aip.org/content/aip/journal/apl/72/25?ver=pdfcov

Published by the AIP Publishing

\section{Articles you may be interested in}

Trapping of negative and positive charges in $\mathrm{Ge}+$ ion implanted silicon dioxide layers subjected to high-field electron injection

J. Appl. Phys. 94, 4440 (2003); 10.1063/1.1604934

Luminescence, radiation damage, and color center creation in Eu 3+-doped Bi 4 Ge 3012 fiber single crystals J. Appl. Phys. 93, 5131 (2003); 10.1063/1.1563816

Photorefractive index gratings in $\mathrm{SnO} 2$ :SiO 2 optical fibers

Appl. Phys. Lett. 76, 807 (2000); 10.1063/1.125591

Stress-dependent growth kinetics of ultraviolet-induced refractive index change and defect centers in highly Gedoped SiO 2 core fibers

Appl. Phys. Lett. 75, 2178 (1999); 10.1063/1.124957

Dynamics of infrared absorption caused by hydroxyl groups and its effect on refractive index evolution in ultraviolet exposed hydrogen loaded $\mathrm{GeO} 2$-doped fibers

Appl. Phys. Lett. 72, 3109 (1998); 10.1063/1.121562

\section{AlP Re-register for Table of Content Alerts}

\section{Create a profile. \\ Sign up today!}

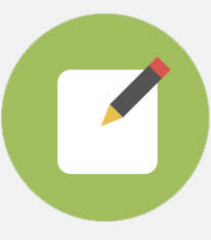




\title{
Uniform component of index structure induced in $\mathrm{Ge}-\mathrm{SiO}_{2}$ fibers by spatially modulated ultraviolet light
}

\author{
Tsung-Ein Tsai, ${ }^{\text {a) }}$ Glen M. Williams, ${ }^{\text {a) }}$ and E. J. Friebele \\ Naval Research Laboratory, Washington, DC 20375
}

(Received 15 January 1998; accepted for publication 20 April 1998)

\begin{abstract}
Experimental data are presented to show that $\mathrm{Ge}(1)$ and $\mathrm{Ge}(2)$ centers are induced by trapping photoinduced electrons from the conduction band, in agreement with our previous proposal that both are trapped electron centers. The spacing $(\Lambda)$ dependence of ultraviolet (UV) light bleaching of the pre-existing $\mathrm{Ge} E^{\prime}$ centers illustrates that the electron diffusion length is greater than $\Lambda$ of the spatially modulated UV light used in the fabrication of fiber Bragg gratings (FBGs) with Bragg wavelengths $\leqslant 1.5 \mu \mathrm{m}$ (short period grating) for laser powers as low as $25 \mathrm{~mJ} / \mathrm{cm}^{2}$. The Ge(1) and $\mathrm{Ge}(2)$ centers are uniformly induced by the spatially modulated UV light and therefore contribute to the uniform component of the index structure of FBGs. [S0003-6951(98)01325-4]
\end{abstract}

Fiber grating devices are emerging as critical components for telecommunications and for sensor applications. ${ }^{1}$ However, the physical structures associated with the index of fiber Bragg gratings (FBGs) have not been totally identified: The structures associated with the index modulation $\left(\Delta n_{\text {mod }}\right)$ of FBGs in unloaded $\mathrm{Ge}^{-\mathrm{SiO}_{2}}$ core fibers that have been identified are $\mathrm{Ge} E^{\prime}$ centers $^{2}$ and densification. ${ }^{2-4}$ In $\mathrm{H}_{2}$-loaded fibers, besides the association of $\mathrm{Ge} E^{\prime}$ and densification, $\mathrm{GeH}$ was also found ${ }^{2}$ to contribute to $\Delta n_{\bmod }$ of the FBG.

High concentrations of $\mathrm{Ge}(1)$ and $\mathrm{Ge}(2)$ are photoinduced along with $\mathrm{Ge} E^{\prime}$ centers in the FBG fabrication process using a pulsed UV laser. ${ }^{2}$ One thing that remains to be elucidated is the contribution of $\mathrm{Ge}(1)$ and $\mathrm{Ge}(2)$ centers to the index structure of FBGs via their optical absorptions ${ }^{5}$ at 4.4 and $5.8 \mathrm{eV}$, respectively, through the Kramers-Kronig relationship.

Photobleaching of pre-existing Ge $E^{\prime}$ centers in Gedoped silica fibers was reported previously, ${ }^{6}$ and bleaching of these centers due to reactions with injected electrons and

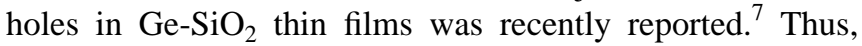
photobleaching of pre-existing Ge $E^{\prime}$ centers by reactions with photoinduced electrons and holes can be used to study their diffusion into the dark regions using a spatially modulated UV light exposure.

In an ideal exposure through a 50\% duty cycle amplitude grating with period $2 \Lambda$, the fraction of electrons or holes that diffuse into the dark regions is about $2 L_{d} / \Lambda$, where $L_{d}$ is the diffusion length of carriers (electrons or holes). For $\Lambda$ comparable to $L_{d}$, a significant fraction of the photoinduced carriers can diffuse into the dark regions. This process reduces the population of defects induced in the light regions by trapping of these carriers. And if the intensity of UV laser light is chosen such that the concentration of the photoinduced carriers is comparable to that of pre-existing Ge $E^{\prime}$ centers, bleaching of these Ge $E^{\prime}$ centers by the carriers diffused into the dark regions is dominant. [In the case of uniform exposure with $\Lambda=0$ reported in this letter (see Fig.

\footnotetext{
a) Also with the Fiber \& Electro-Optics Research Center, Virginia Polytechnic Institute, Blacksburg, VA 24061.
}

2 ), the observation of complete photobleaching of preexisting $\mathrm{Ge} E^{\prime}$ centers in $\mathrm{Ge}-\mathrm{SiO}_{2}$ suggests that bleaching has occurred before trapping to form $\mathrm{Ge}(1)$ and $\mathrm{Ge}(2)$ defects.] The diffusion length of the carriers can then be studied by photobleaching the pre-existing $\mathrm{Ge} E^{\prime}$ centers.

In our experiments, uncoated $\mathrm{Ge}-\mathrm{SiO}_{2}$ core single mode fiber that contains $10^{17} / \mathrm{cm}^{3}$ pre-existing Ge $E^{\prime}$ centers was exposed to a single pulse of $\mathrm{KrF}$ laser light through a $50 \%$ duty cycle amplitude grating (Photo Sciences, Inc., CA) of grating period $2 \Lambda$ with $\Lambda \geqslant 3 \mu \mathrm{m}$. Single pulse $\mathrm{KrF}$ exposure was used to avoid complications due to multishot effects. Paramagnetic defects induced in the exposed fibers were studied by use of electron spin resonance (ESR) on $\approx 1 \mathrm{~cm}$ sample lengths of fiber of total length $96 \mathrm{~cm}$ loaded into the sample tube. Computer simulations of ESR spectra were carried out to obtain the populations of the observed paramagnetic defects.

Figure 1 shows the $\mathrm{Ge}(1)$ and $\mathrm{Ge}(2)$ populations induced by 25 and $15 \mathrm{~mJ} / \mathrm{cm}^{2} \mathrm{KrF}$ laser pulses in $\mathrm{Ge}-\mathrm{SiO}_{2}$ core fibers as a function of $\Lambda$. For the $25 \mathrm{~mJ} / \mathrm{cm}^{2}$ exposure, the induced populations of $\mathrm{Ge}(1)$ and $\mathrm{Ge}(2)$ for $\Lambda \geqslant 8 \mu \mathrm{m}$ are about half that of the uniform exposure $(\Lambda=0 \mu \mathrm{m})$, as anticipated for $50 \%$ duty cycle amplitude grating exposures. For $\Lambda$ $\leqslant 5 \mu \mathrm{m}$, the populations of $\mathrm{Ge}(1)$ and $\mathrm{Ge}(2)$ decrease to $\sim 30 \%$ of the uniform exposure, suggesting the loss of $20 \%$ of the photoinduced carriers in the light regions. Thus, the fraction of carriers that diffuse into dark regions, $2 L_{d} / \Lambda$, is $\approx 0.2$, and for $\Lambda=5 \mu \mathrm{m}, L_{d}$ is $\approx 0.5 \mu \mathrm{m}$.

For the $15 \mathrm{~mJ} / \mathrm{cm}^{2}$ exposure, the decrease in the populations of the $\mathrm{Ge}(1)$ and $\mathrm{Ge}(2)$ centers appears to occur $\sim 3 \mu \mathrm{m}$, as shown in Fig. 1, although it is only slightly greater than the variations in observed defect populations due to pulse-to-pulse variations in laser power. However, the populations with $\Lambda=3 \mu \mathrm{m}$ are less than the largest variation from the average of the populations. Using this value, a diffusion length $\approx 0.3 \mu \mathrm{m}$ is obtained. The carrier diffusion length is found to increase with laser power (15 vs $25 \mathrm{~mJ} / \mathrm{cm}^{2}$ ), implying that their diffusion is photoassisted. Note from Fig. 1 that the average population ratio of $\mathrm{Ge}(1)$ 


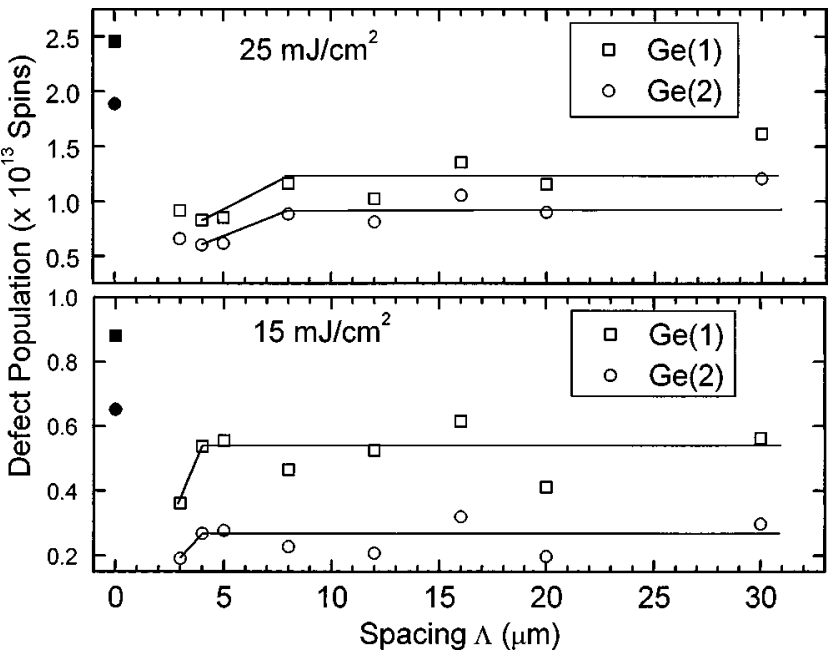

FIG. 1. Ge(1) and $\mathrm{Ge}(2)$ defect center populations observed in $1 \mathrm{~cm}$ lengths of $\mathrm{Ge}-\mathrm{SiO}_{2}$ core fibers of total length $96 \mathrm{~cm}$ after exposure to a single pulse of a $\mathrm{KrF}$ laser through amplitude gratings of various spacing (open points). The solid lines are draw to aid the eyes. The solid points are for uniform exposure.

and $\mathrm{Ge}(2)$ centers induced by 25 and $15 \mathrm{~mJ} / \mathrm{cm}^{2}$ pulses is $0.38 \pm 0.02$, which is equal to $(25 / 15)^{2}=0.36$ within experimental error. This result supports the hypothesis that $\mathrm{Ge}(1)$ and $\mathrm{Ge}(2)$ are induced by two-photon absorption processes. ${ }^{8}$

The similarity in $\Lambda$ dependence of the induced populations of $\mathrm{Ge}(1)$ and $\mathrm{Ge}(2)$ centers shown in Fig. 1 suggests that both are generated by trapping of carriers with comparable mobilities, i.e., either electrons or holes but not both since the electron mobility in $\mathrm{SiO}_{2}$ is nine orders of magnitude greater than that of the holes as reported by Hughes. ${ }^{9}$ This is in disagreement with the proposal ${ }^{10}$ that $\mathrm{Ge}(1)$ is an electron trapping center, while $\mathrm{Ge}(2)$ is a hole trapping center. The diffusion length of $\approx 1 \mu \mathrm{m}$ calculated above suggests that the trapped carriers are electrons trapped from the conduction band of $\mathrm{Ge}_{-} \mathrm{SiO}_{2}$, in agreement with our proposal ${ }^{11}$ that both $\mathrm{Ge}(1)$ and $\mathrm{Ge}(2)$ are trapped electron centers. This is also consistent with the conclusion that these are induced by two-photon absorption processes since excitation of electrons from the valence to the conduction band in ${\mathrm{Ge}-\mathrm{SiO}_{2}}_{2}$ (band gap ${ }^{8} \approx 7.2 \mathrm{eV}$ ) requires two $\mathrm{KrF}$ photons $\left(h_{v}=5 \mathrm{eV}\right)$.

To accurately estimate the electron diffusion length, the $\Lambda$-dependent photobleaching of pre-existing Ge $E^{\prime}$ centers was analyzed using a one-dimensional diffusion model of electrons along the fiber axis $z$. Among the photoinduced electrons, only those located at the boundary of the light and dark regions within a length, $\delta$, of the order of electron diffusion length can diffuse into dark regions. The total population of electrons involved in diffusion is then $n_{e} \delta$, where $n_{e}$ is the photoinduced electron concentration. With a $50 \%$ duty cycle amplitude grating exposure of spacing $\Lambda$, the remaining pre-existing Ge $E^{\prime}$ center population $\left[\mathrm{Ge}^{\prime}\right]_{r}$ in a period $2 \Lambda$ can be calculated as

$$
\begin{aligned}
{\left[\mathrm{Ge} E^{\prime}\right]_{r}=} & \int_{z_{0}}^{\Lambda-z_{0}}\left[\left(\mathrm{Ge} E_{p}\right)-\frac{n_{e} \cdot \delta}{\sqrt{\pi} \cdot L_{d}}\right. \\
& \cdot\left[e^{-\left(z / 2 L_{d}\right)^{2}}+e^{\left.-\left[(\Lambda-z) / 2 L_{d}\right]^{2}\right]}\right] d z .
\end{aligned}
$$

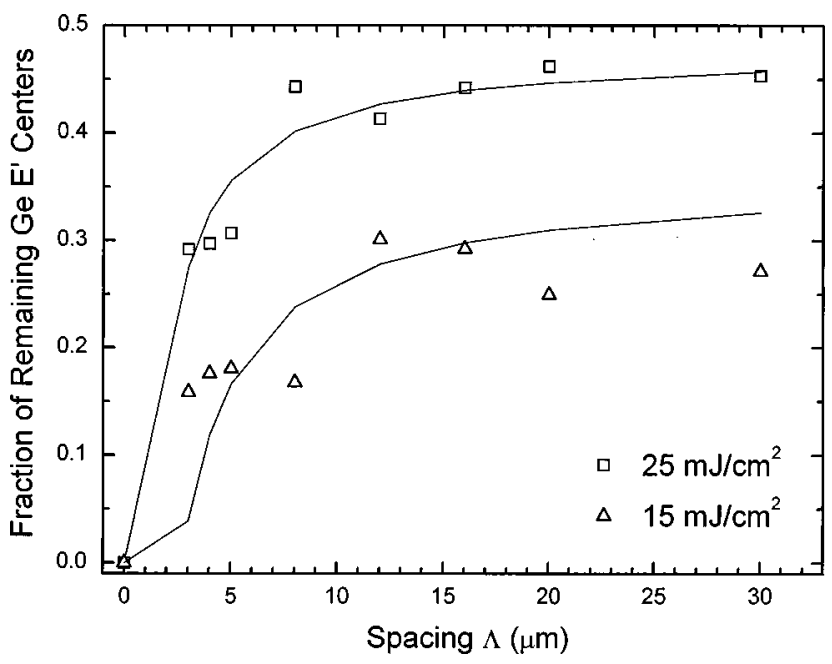

FIG. 2. Fraction of remaining Ge $E^{\prime}$ centers after exposure to single pulse of $\mathrm{KrF}$ laser through amplitude gratings of various spacing $\Lambda$ (points). The solid lines are fits to Eq. (3) for the $15 \mathrm{~mJ} / \mathrm{cm}^{2}$ exposure with $L_{d}$ $=0.2 \mu \mathrm{m}, z_{0}=0.49 \mu \mathrm{m}$, and $f_{d}=0.02$, and for the $25 \mathrm{~mJ} / \mathrm{cm}^{2}$ exposure with $L_{d}=0.3 \mu \mathrm{m}, z_{0}=0.81 \mu \mathrm{m}$, and $f_{d}=0.14$.

where $\left(\mathrm{Ge} E_{p}\right)$ is the concentration of pre-existing Ge $E^{\prime}$ centers and $z_{0}$ is the diffusion distance below which total bleaching of pre-existing Ge $E^{\prime}$ centers occurs. $Z_{0}$ satisfies the following equation:

$$
\left(\mathrm{Ge} E_{p}\right)=\frac{n_{e} \cdot \delta}{\sqrt{\pi} \cdot L_{d}} \cdot\left[e^{-\left(z_{0} / 2 L_{d}\right)^{2}}+e^{-\left[\left(\Lambda-z_{0}\right) / 2 L_{d}\right]^{2}}\right] .
$$

The fraction of remaining $\mathrm{Ge} E^{\prime}$ centers, $f_{\mathrm{Ge} E^{\prime}}$ $=\left[\mathrm{Ge}^{\prime}\right]_{r} /\left[2 \Lambda\left(\mathrm{Ge} E_{p}\right)\right]$, is then

$$
\begin{aligned}
f_{\mathrm{Ge} E^{\prime}}= & \frac{1}{2}-\frac{z_{0}}{\Lambda}-\sqrt{\pi} \cdot \frac{L_{d}}{\Lambda\left[e^{-\left(z_{0} / 2 L_{d}\right)^{2}}+e^{\left[\left(\Lambda-z_{0}\right) / 2 L_{d}\right]^{2}}\right]} \\
& \cdot\left[\operatorname{erf}\left(\frac{\Lambda-z_{0}}{2 L_{d}}\right)-\operatorname{erf}\left(\frac{z_{0}}{2 L_{d}}\right)\right], \quad \Lambda>2 z_{0} \\
= & 0, \quad \Lambda \leqslant 2 z_{0},
\end{aligned}
$$

where

$$
\operatorname{erf}(x)=\frac{2}{\sqrt{\pi}} \cdot \int_{0}^{x} e^{-y^{2}} d y .
$$

Figure 2 shows the fraction of remaining Ge $E^{\prime}$ centers as a function of $\Lambda$ for laser powers of 15 and $25 \mathrm{~mJ} / \mathrm{cm}^{2}$. The solid lines are fits using Eq. (2) with $z_{0}$ and $L_{d}$ as adjustable parameters and an additional parameter, $f_{d}$, which is the fraction of $\mathrm{Ge} E^{\prime}$ centers bleached by UV light diffracted into the dark regions. (Since the amplitude gratings used in our experiments consist of $1000 \AA$ chrome with an optical density of 3.0 to 3.2 in the UV and they have an antireflective coating, we assume no UV light transmission or scattering into dark regions. However, a calculation using the geometry of our setup indicates that up to $6 \%$ of the UV photons in the light region are diffracted into dark regions.) From the fit of the data in Fig. 2, the electron diffusion lengths are found to be 0.19 and $0.26 \mu \mathrm{m}$ for the 15 and $25 \mathrm{~mJ} / \mathrm{cm}^{2}$ exposures, respectively, consistent with the above conclusion that the diffusion of electrons is photoassisted. To the best of our knowledge, this is the first report of the elec- 


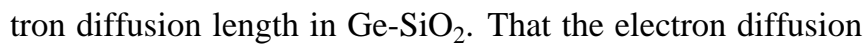
length is about $1 \mu \mathrm{m}$ provides additional support for the electric-field-induced second-harmonic generation (SHG) mechanism ${ }^{12}$ in ${\mathrm{Ge}-\mathrm{SiO}_{2}}_{2}$ core fibers, for which charge migration over macroscopic distance $(>1 \mu \mathrm{m})$ is needed.

The period of the spatially modulated UV light for fabricating FBGs with Bragg wavelengths $\leqslant 1.5 \mu \mathrm{m}$ is $\leqslant 0.3 \mu \mathrm{m}$, which is comparable to the electron diffusion length of $\approx 0.3 \mu \mathrm{m}$ estimated in the $25 \mathrm{~mJ} / \mathrm{cm}^{2} \mathrm{KrF}$ exposures. Thus, about the same concentrations of $\mathrm{Ge}(1)$ and $\mathrm{Ge}(2)$ centers are induced in the dark and light regions. Since

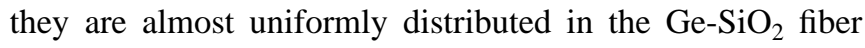
core, they contribute to the uniform component of the index of FBGs.

In summary, the $\Lambda$ dependence of $\mathrm{Ge}(1)$ and $\mathrm{Ge}(2)$ centers photoinduced by spatially modulated UV light in $\mathrm{Ge}-\mathrm{SiO}_{2}$ core fibers suggests that they are induced by trapped electrons from the conduction band. The electron diffusion length, obtained from the $\Lambda$ dependence of bleaching of preexisting Ge $E^{\prime}$ centers, is found to be equal to or greater than the spacing of the spatially modulated UV light used for fabricating short period, fiber Bragg gratings for $\mathrm{KrF}$ laser powers as low as $25 \mathrm{~mJ} / \mathrm{cm}^{2}$. $\mathrm{Ge}(1)$ and $\mathrm{Ge}(2)$ centers are therefore almost uniformly induced throughout the exposed fiber core and thus contribute to the uniform component of the index of FBGs in $\mathrm{Ge}-\mathrm{SiO}_{2}$ fibers.
This work was partially supported by the Office of Naval Research. One of the authors (T.-E.T.) acknowledges the partial support of National Science Foundation under Grant No. ECS-9530329.

${ }^{1}$ K. O. Hill, P. St. J. Russell, G. Meltz, and A. M. Vengsarkar, J. Lightwave Technol. 15, 1261 (1997).

${ }^{2}$ T. E. Tsai, G. M. Williams, and E. J. Friebele, Opt. Lett. 22, 224 (1997).

${ }^{3}$ B. Poumellec, P. Guènot, I. Riant, P. Sanaonetti, P. Niay, P. Bernage, and J. F. Bayon, Opt. Mater. 4, 441 (1995).

${ }^{4}$ P. Y. Fonjallaz, H. G. Limberger, R. P. Salathé, F. Cochet, and B. Leuenberger, Opt. Lett. 20, 1346 (1995).

${ }^{5}$ E. J. Friebele and D. L. Griscom, in Defects in Glasses, edited by F. L. Galeener, D. L. Griscom, and M. J. Weber [ Mater. Res. Soc. Symp. Proc. 61, 319 (1986)].

${ }^{6}$ T. E. Tsai, C. G. Askins, and E. J. Friebele, Appl. Phys. Lett. 61, 1 (1992); T. E. Tsai and D. L. Griscom, Proc. SPIE 1516, 14 (1991).

${ }^{7}$ W. L. Warren, K. Simmons-Potter, B. G. Potter, Jr., and J. A. Ruffner, Appl. Phys. Lett. 69, 1453 (1996).

${ }^{8}$ H. Hosono, H. Kawazoe, and J. Nishii, Phys. Rev. B 53, R11921 (1996).

${ }^{9}$ R. C. Hughes, Phys. Rev. B 15, 2012 (1977).

${ }^{10}$ E. V. Anoikin, A. N. Gusovsky, D. D. Gusovsky, V. M. Mashinsky, S. I. Miroshnichenko, V. B. Neustruv, V. A. Tikhomirov, and Yu B. Zerv, Sov. Lightwave Commun. 1, 123 (1991).

${ }^{11}$ T. E. Tsai, D. L. Griscom, and E. J. Friebele, Diffus. Defect Data 53-54, 469 (1987).

${ }^{12}$ W. Margulis, F. Laurell, and B. Lesche, Nature (London) 378, 699 (1995). 